\title{
Misconceptions about substance use in the US-Mexico border area
}

\author{
There is a widespread misconception that drug use is rife in the US-Mexico border area, \\ particularly in Mexican states. But with a dirth of available epidemiological data, we have \\ to be careful about the conclusions we draw, argues Guilherme Borges.
}

$\mathrm{T}$ he US-Mexico border area has received a great deal of negative attention because of the so-called war on drugs and its devastating social and health consequences. A byproduct of this situation is a widespread misperception about drug use in the US-Mexico border area. In fact, we know very little about drug use in this area, but we tend to overgeneralize from the few studies we have. These misperceptions have added to the stigma around drug users that further detracts from appropriate healthcare actions.

With about $30 \%$ of the US population in border states being of Mexican ancestry, and up to $70 \%$ being of Mexican origin in some metropolitan border counties, cultural and genetic similarities between both sides of the border abound. Mexicans that have lived in the United States and have come back to Mexico and families with a migrant member in the United States have higher rates of drug use than Mexicans without any migration experience or migrant connections. The evidence is still limited but shows that Mexican people deported from the United States also have an increased prevalence of drug use. We know close to nothing about drug use among internal Mexican migrants to the north border cities and among those waiting to cross to the US side of the border.

\section{These misperceptions have added to the stigma around drug users that further de- tracts from appropriate healthcare actions.}

There have been epidemiological surveys of drug use in some northern cities in Mexico over the past four decades and national surveys approximately every five years from 1988 to 2016 (https://go.nature. com/2OvOeQ9). These national surveys provide national and regional estimates of drug use, but some also include additional standalone surveys in northern border cities. From the limited data available, the 12-month prevalence of drug use ranges from $4 \%$ in Tijuana to $7.4 \%$ in Nuevo Laredo, compared with a national prevalence of $2.9 \%$.

With such scarcity of data, we have to be careful about the conclusions we draw. First, it has been stated that Mexican border cities have higher rates of drug use than Mexican non-border cities. However, most data comparisons are unadjusted and only compare the cities of Tijuana, Ciudad Juarez, Matamoros and Nuevo Laredo with the city of Monterrey, which has a lower prevalence of drug use than the national figures. Second, the northern states of Mexico have a higher prevalence of drug use than the rest of the country. But if we use the most recent data from Encuesta Nacional de Consumo de Drogas, Alcohol y Tabaco (ENCODAT) 2016 (https://go.nature.com/2OvOeQ9), only three of the six states that share a border with the United States have a lifetime prevalence of drug use that is higher than the national level. Third, although there is increased drug use in the northern border areas due to drug trafficking activities, the increase in prevalence of drug use in four border cities was below the national level of increase, and in only two cities was the increase in drug use higher than the national level. Fourth, and arguably most importantly, the national mean prevalence of drug use in Mexico, the prevalence of drug use in north Mexican border states and the prevalence in Mexican border cities are all below the corresponding rates of drug use on the other side of the border (that is, in the United States). There is only one truly binational survey between sister cities over the same time period and using the same instruments that also makes basic adjustments for demographic factors. In this survey, higher rates of drug misuse were found in US cities compared with their cross-border Mexican counterparts.

From the little we know, it is apparent that drug use represents a tangible threat in the northern border cities. Among other consequences, human immunodeficiency virus (HIV) and other sexually transmitted diseases spread, alcohol use disorders and mental health comorbidity surface, and violence associated with the criminalization of these behaviours emerges. Nevertheless, we should avoid generalizations that erroneously show the area as a 'living hell'. The north of Mexico is one of the most industrious and dynamic parts of the country and the border regions, on both sides of the border, are rich, challenging and understudied environments. To reduce these cities and areas to places where rampant drug use exists is an overstatement that ignores the full scope of the life in these cities.

Everywhere in Mexico there is a big gap between the presence of substance use and substance use disorders and the availability of treatment. The only epidemiological study among people with alcohol and drug use problems in three border cities suggests that only $5.3 \%$ of people surveyed received help for their problems (J. Immigr. Minor. Health 19, 1174-1185; 2017). While some of the northern border cities offer services for the treatment of drug use disorders that are diverse and state of the art, most people with substance use disorders and its consequences - such as HIV, hepatitis and sexually transmitted diseases - are left with few choices or are simply abandoned to their fate.

If we want to reach beyond the misperceptions about drug use in the USMexico border area and simple stereotypes of drug addicts that cannot be treated and failed authorities incapable of treating them, the Mexican northern border cities and their communities have to be understood in the so-called risk environment contexts in all their complexity.

\section{Guilherme Borges}

Instituto Nacional de Psiquiatria Ramon de la Fuente Muniz, Ciudad de Mexico, Mexico.

e-mail:guibor@imp.edu.mx

Published online: 26 November 2018 https://doi.org/10.1038/s41562-018-0475-4

Competing interests

The author declares no competing interests. 